\title{
Short Communication: Can Wireless Ear buds with Smartphone App Act as a Substitute for Hearing Aids?
}

\author{
Neha Taneja* \\ Department of Audiology and Speech Language Pathology, Amity University Haryana, India
}

Submission: November 06, 2017; Published: November 10, 2017

*Corresponding author: Neha Taneja, Assistant Professor- II, Department of Audiology and Speech Language Pathology, Amity University Haryana, India, Tel: +91 8860592030

\section{Short Communication}

Wireless ear buds stream audio from smart phones, computers and other devices via Bluetooth (BT) technology. They enable users a friendly option to enjoy hand free phone calls and other kinds of listening requirements with ease, without any physical connection [1]. These wireless ear buds were developed with intent of serving active listening with hand free options and not as a hearing aid. However many manufacturers have come out with a idea that these wireless ear buds when paired with the smart phones and apps can act like hearing aid to stimulate many options as found in hearing aids such as regulating volume control, noise cancellation etc.

For people who use hearing aids, the mechanism of sound transmission is performed in two ways. Firstly sound travels directly to ear canal around hearing aid or pass the ear mold. This is called direct mode of sound transmission to ear canal. Open canal fittings and normal hearing facilitates the greater emphasis of this pathway. The other pathway transmits the sound directly through the hearing aid to the ear canal [2]. The concept of latency is an important factor for the hearing aid wearers. Hearing aids requires time to process and amplify live sound. The acoustic output from hearing aid is delayed with respect to the original live sound. Latency is defined as the difference between the time of the original sound and the time when the amplified sound leaves from the hearing aid [1].

Even though the latency is measured in milliseconds it can affect the sound quality of speech signal. With $10 \mathrm{~ms}$ direct sound and amplified sound can interact with each other which alter the timbre of sound, usually when the delay becomes longer than the direct sound patient may notice "echo effect" [2]. This may lead to synchronization failure of auditory information with the visual information and interfere in speech reading [1]. Hearing aid delay has been related to the severity of hearing loss. As the hearing threshold worsens the delay is often unnoticed as the individual hears less direct sound and the delay becomes unnoticeable. The other reason for this is that the hearing threshold worsens the physical fitting becomes tighter which further attenuates the direct sound and thereby reduces the possibility of delay [2]. The tolerable delay time has been found to be varied as per the degree of hearing loss.

According to some authors such as Stone and Colleagues delay time tolerable for mild to moderate hearing losses can be as low as 20 to $30 \mathrm{~ms}$ and speech is found to be affected if the delay exceeds $30 \mathrm{~ms}$. Contrastingly the other author documents the speech production and quality can even be affected for the delays as small as $10 \mathrm{~ms}$ [2]. Other set of study supported that the processing delay of 5 and $6 \mathrm{~ms}$ may be required to avoid compromises in sound quality. With the introduction of digital technology and digital hearing aids, it has been found that the digital hearing aid has more latency as compared to analog hearing aids. Each "feature" of the digital hearing instrument can add to the total group delay. More the number of channels much more sophisticated feedback reduction system and advanced digital noise reduction system may lead to more delay [2].

The type of signal processing also plays an important role as a deciding factor for the delay. The two major types of signal processing and frequency analysis are Filter Bank and Fast Fourier Transformation. Both these approaches believes that as temporal resolution is increased spectral resolution will decrease and viceversa. Irrespective of either of methods used for signal processing the more sophisticated signal processing leads to hearing aid delay as when the signal travels through number of processors [2]. Latency is a factor based on which hearing aids cannot be substituted for wireless ear buds with smart phone app. Even though smart phone app paired with wireless ear buds constitutes same system requirement as like a hearing aid. Though there are many advantages of smart phones based hearing aid applications paired with wireless ear buds such as

a) It is not limited by the negative perceptions associated with stigma 
b) helps to create hearing awareness

c) they are cheaper as compared to hearing aids

d) They offer the advantage to users about temper decline in cognitive function stemming from the prolonged auditory desensitization.

Despite of the many advantages of smart phone based hearing aid, it cannot be substituted for hearing aids as they just provide temporary assistance to individuals with hearing deficits [2]. These Bluetooth enabled ear buds create an unacceptable amount of delay in the signal. This creates a disturbing loss of audiovisual synchronization and interferes with speech reading. Smartphone enabled system is not practical for live listening assistance. This smart phone enabled system can only facilitate hearing device volume, receive phone calls and stream music and audio directly to the hearing aid. These are impractical for wireless live hearing assistance via apps on mobile phones. There is too much latency.

\section{Conclusion}

Previous studies have shown that the hearing aid delay contributes to signal distortion when the amplified sound transmission is mixed with direct path. Smartphone based hearing aid applications can only provide temporary assistance to individuals with hearing deficits $[1,3]$. In specific smart phone based applications only helps to adjust frequency gain response, adjust volume etc but till date there is no evidence for the practical basis of how smart phones based hearing aid applications can improve adoption rates and substitute with hearing aids. At least hearing care professionals can be confident to inform their patients that similar wireless Bluetooth ear buds with smart phone app are no substitute for hearing aids as the BT ear buds with smart phones enabled hearing aid apps produce much more latency and distorts the speech intelligibility [1].

\section{References}

1. Einhorn R (2017) Can Apple airpods be used as hearing aids. The Hearing Review.

2. Heurig R, Chalupper J (2010) Acceptable Processing Delay in Digital Hearing Aids. Hearing Review 17(1): 28-31.

3. Amlani A, B Taylor, C Levy, R Robbins (2013) Utility of smartphone-based hearing aid applications as a substitute to traditional hearing aids. Hearing Review 16-23.

\section{Your next submission with Juniper Publishers will reach you the below assets}

- Quality Editorial service

- Swift Peer Review

- Reprints availability

- E-prints Service

- Manuscript Podcast for convenient understanding

- Global attainment for your research

- Manuscript accessibility in different formats ( Pdf, E-pub, Full Text, Audio)

- Unceasing customer service

Track the below URL for one-step submission https://juniperpublishers.com/online-submission.php 